\title{
Fenton-Type Reactions and Iron Concentrations in the Midgut Fluids of Tree-Feeding Caterpillars
}

\author{
Raymond Barbehenn, ${ }^{*}$ Todd Dodick, Umpai Poopat, and Brooke Spencer \\ Peroxides are formed in the midgut fluids of caterpillars when ingested tannins and other phenolic compounds oxidize. If these \\ peroxides broke down in the presence of redox-active metal ions, they would form damaging free radicals (Fenton-type \\ reactions). Elemental iron is present in relatively large amounts in leaves and artificial diets, but little is known about its \\ concentration and redox state in midgut fluids, or the extent of Fenton-type reactions in these conditions. This study compared \\ the levels of hydroxyl radicals and iron in the midgut fluids of two species of caterpillars: Orgyia leucostigma, in which phenol \\ oxidation is limited, and Malacosoma disstria, in which phenol oxidation is more extensive. We tested two hypotheses: (1) \\ higher levels of hydroxyl radicals are formed in M. disstria (consistent with the higher concentrations of hydrogen peroxide in \\ this species), and (2) lower concentrations of iron are present in 0 . leucostigma (providing greater protection of its midgut \\ fluids from oxidative damage). Hydroxyl radical levels increased greatly in M. disstria, but not in 0 . leucostigma, when they \\ consumed a tannin-containing diet, supporting the first hypothesis. Protein oxidation was also significantly increased in the \\ midgut fluids of $M$. disstria that ingested tannic acid, consistent with hydroxyl radical damage. Contrary to the second hypoth- \\ esis, similar concentrations of iron $(70 \mu \mathrm{M})$ remained in solution or suspension in both species of caterpillars on an artificial \\ diet. Over $90 \%$ of this iron appeared to be in the reduced (catalytically active) state in both species. We conclude that tree- \\ feeding caterpillars protect their midgut fluids from oxidative damage caused by Fenton-type reactions by limiting the forma- \\ tion of peroxides, rather than by limiting the availability of reduced iron. Arch. Insect Biochem. Physiol. 60:32-43, 2005. \\ (c) 2005 Wiley-Liss, Inc.
}

Keywords: Fenton reaction; iron; peroxides; oxidation; phenols; free radicals; caterpillars

\section{INTRODUCTION}

Phenolic compounds, such as tannins and low molecular weight phenolic acids, are among the most common and chemically diverse defensive allelochemicals produced by plants (Hagerman and Butler, 1991; Okuda et al., 1993; Bravo, 1998). These compounds may be active against folivorous insects by deterring feeding, or by acting as prooxidants or toxins following ingestion (Hagerman and Butler, 1991; Summers and Felton, 1994). Previous studies have shown that ingested phenolic compounds have greater prooxidant activity in the phenol-sensitive caterpillar Malacosoma disstria (Lasiocampidae) than in the phenol-tolerant species Orgyia leucostigma (Lymantriidae) (Barbehenn and Martin, 1992, 1994; Barbehenn et al., 2003a). As a result of the oxidation of phenolic compounds in the midgut lumen, hydrogen peroxide $\left(\mathrm{H}_{2} \mathrm{O}_{2}\right)$ and organic hydroperoxides $(\mathrm{ROOH})$ are produced in higher concentrations in the midgut fluids of M. disstria than in O. leucostigma (Barbehenn et al., 2001; unpublished data).

Peroxides are themselves relatively unreactive, but break down to form highly reactive free radicals in the presence of reduced iron [Fe (II)] or

Departments of Molecular, Cellular and Developmental Biology and Ecology and Evolutionary Biology, University of Michigan, Ann Arbor

Contract grant sponsor: NSF; Contract grant number: IBN-9974583.

*Correspondence to: Raymond Barbehenn, Departments of Molecular, Cellular and Developmental Biology and Ecology and Evolutionary Biology, University of Michigan, Ann Arbor, Ml 48109-1048. E-mail: rvb@umich.edu

Received 21 August 2004; Accepted 4 April 2005

(C) 2005 Wiley-Liss, Inc.

DOI: 10.1002/arch.20079

Published online in Wiley InterScience (www.interscience.wiley.com) 
other transition metal ions and their complexes (Reactions 1 and 2) (Halliwell and Gutteridge, 1986; Buettner, 1993).

(1) Hydroxyl radical (Fenton reaction)

$$
\mathrm{H}_{2} \mathrm{O}_{2}+\mathrm{Fe}(\mathrm{II}) \rightarrow \mathrm{HO}^{-}+\mathrm{OH}^{-}+\mathrm{Fe}(\mathrm{III})
$$

(2) Alkoxyl radical

$$
\mathrm{ROOH}+\mathrm{Fe}(\mathrm{II}) \rightarrow \mathrm{RO}+\mathrm{OH}^{-}+\mathrm{Fe}(\mathrm{III})
$$

In biological systems, Fe (II) that is not sequestered by iron-binding proteins forms a wide variety of complexes, many of which remain catalytically active (Halliwell and Gutteridge, 1986; Buettner, 1993). Hydroxyl and alkoxyl (or peroxyl) radicals readily oxidize cellular components and degrade the nutritional quality of food in the gut lumen (Summers and Felton, 1994; Felton, 1996; Halliwell and Gutteridge, 1999), and ingested iron has been shown to cause oxidative stress in houseflies (Sohal et al., 1985). However, little is known about the extent to which peroxides in the gut fluids of herbivorous insects take part in Fenton-type reactions.

Iron is the most abundant redox-active metal in the host plants of herbivorous insects (Guha and Mitchell, 1966; Welch et al., 2002). For example, iron concentrations in the aqueous fractions of the leaves of 26 species of woody plants range from 220 to $2,100 \mu \mathrm{M}$ (our calculation) (Allen, 1974). Iron is commonly present in a similar range of concentrations in caterpillar artificial diets (e.g., 1,000 $\mu \mathrm{M}$ in this study). These levels are over 20 -fold higher than those of other redox-active metals, such as copper (Allen, 1974). The large amount of iron in the food of herbivorous insects suggests the potential for extensive radical-forming reactions in their gut fluids, but little is known about the concentration of iron that remains in solution in the highly alkaline midguts of caterpillars.

Previous work has shown that roughly $10 \%$ of ingested iron remains in solution or colloidal suspension in the midgut fluids of O. leucostigma and Manduca sexta caterpillars (Barbehenn and Martin, 1998). However, even iron concentrations on the order of $50 \mu \mathrm{M}$ are capable of catalyzing extensive Fenton-type reactions if $\mathrm{Fe}$ (II) is maintained at this level by redox cycling, such as by ascorbate.
Therefore, it is possible that ingested iron plays an important role in oxidative processes in herbivorous insects, but no work has been done, to our knowledge, on the redox state of iron in their gut fluids.

One purpose of this study was to extend our previous work on peroxides in the midgut fluids of M. disstria and O. leucostigma by examining hydroxyl radical levels in these tree-feeding caterpillars. Specifically, this study tested the hypothesis that higher levels of hydroxyl radicals are formed in caterpillars containing higher levels of hydrogen peroxide (i.e., M. disstria > O. leucostigma). Protein oxidation was measured as a marker of free radical damage in the midgut fluid of $M$. disstria. Protein carbonyls are formed by the reaction of hydroxyl or alkoxyl radicals with side chains of amino acids near metal cation binding sites (Levine et al., 1990; Stadtman, 1990; Davies et al., 1999). Thus, the level of protein carbonyls is a particularly relevant marker of Fenton-type reactions.

If hydroxyl radical levels were higher in $M$. disstria than in O. leucostigma, this could be the result of higher hydrogen peroxide concentrations in M. disstria, but it could also result from higher $\mathrm{Fe}$ (II) concentrations in this species. Although previous work has established the importance of maintaining ascorbate in the midgut lumen to limit phenol oxidation (Barbehenn et al., 2001, 2003a), this is not necessarily the entire basis for phenol tolerance in caterpillars. The sequestration of iron in forms that do not take part in Fentontype reactions could also be an important antioxidant defense mechanism (Felton and Summers, 1995). Therefore, we tested the hypothesis that $O$. leucostigma limits the availability of redox-active iron in its midgut fluids to a greater extent than does M. disstria. Finally, we examined whether iron concentrations change along the length of the midgut in M. disstria. It was of interest to determine whether higher concentrations of iron are found in the posterior midgut, a region into which excess iron is secreted and in which the rate of phenol oxidation is greatest (Locke and Nichol, 1992; Barbehenn and Martin, 1994; Barbehenn et al., 2003a). 


\section{MATERIALS AND METHODS}

\section{Insects}

Eggs of M. disstria and O. leucostigma were provided by the Canadian Forest Pest Management Institute (Sault Ste. Marie, Ontario). Larvae were reared on an artificial diet in Petri dishes in incubators (primarily at $23^{\circ} \mathrm{C}, 16 \mathrm{~h}$ light: $8 \mathrm{~h}$ dark) until the final instar. Colonies of both species were maintained at $18^{\circ} \mathrm{C}$ when it was necessary to slow their developmental rates. Final-instar larvae were switched at random to experimental diets, replaced in an incubator at $23^{\circ} \mathrm{C}$, and allowed to feed for 2 days. In the case of $M$. disstria larvae fed oak leaves, an incubator temperature of $18^{\circ} \mathrm{C}$ was used. Freshly-prepared diets were provided daily. On the third day of each experiment, midgut contents were dissected from larvae, weighed, and kept under a nitrogen atmosphere, as described previously (Barbehenn et al., 2001).

\section{Diets}

The rearing diet was prepared as described previously (Barbehenn et al., 2001), with the exception that linseed oil was substituted for wheat germ oil, methyl paraben was omitted, and sodium alginate was included [2.9\% dry diet (DW)]. Iron was provided in Wesson's salts (Sigma Chemical Co., St. Louis, MO) as ferric orthophosphate at a level of at $0.08 \%$ of the total dry ingredients, or $1,000 \mu \mathrm{M}$ if fully solubilized.

Experimental diets were identical to the rearing diet, with the exception that ascorbate was 0.23 or $0.50 \%$ (rather than $2.3 \%$ ) DW. The lower ascorbate concentrations were considered to be closer to those commonly found in host tree foliage (Barbehenn et al., 2003b). Tannic acid (5\% DW; Sigma, lot 20H0278) was added to the test diet. Previous high-performance liquid chromatography (HPLC) characterization of this tannic acid lot showed that it contains approximately $4 \%$ gallic acid and a range of galloyl glucose esters, primarily tri-, tetra-, penta-, and hexagalloyl glucose (Barbehenn et al., 1996). Tannic acid and ascorbic acid remain stable in the diet over a 1-day period at $23^{\circ} \mathrm{C}$ (Barbehenn and Martin, 1992; unpublished data), suggesting that the formation of oxidation products (e.g., protein carbonyls) in the diet was negligible.

\section{Hydroxyl Radicals}

Hydroxyl radicals were measured in gut fluids by including dimethyl sulfoxide (DMSO) in the diet as a non-toxic hydroxyl radical scavenger (Babbs and Steiner, 1990). Hydroxyl radicals that formed in vivo and ex vivo were measured with HPLC (Li et al., 1997, 1999). Briefly, larvae were fed artificial diet containing $0.23 \%$ ascorbate, 5\% (v/v) DMSO, and 0 or 5\% tannic acid. Gut fluid was collected from the anterior and posterior midguts of dissected larvae by dividing the midgut contents in half and extracting the contents of each portion in $150 \mu \mathrm{l}$ of $\mathrm{pH} 9.0$ TRIS buffer (nitrogenpurged, $50 \mathrm{mM})$ containing $5 \%(\mathrm{v} / \mathrm{v})$ DMSO. The headspace of each microcentrifuge tube was flushed with nitrogen. Following centrifugation $(8,000 g, 3$ $\left.\min , 4^{\circ} \mathrm{C}\right)$, supernatant solutions $(100 \mu \mathrm{l})$ were mixed with $10 \mu \mathrm{l}$ of proxyl fluorescamine $(30 \mathrm{mM}$ in DMSO) under a nitrogen atmosphere. Proxyl fluorescamine was synthesized from fluorescamine (Acros Organics, Pittsburgh, PA) and 3-amino2,2,5,5-tetramethyl-1-pyrrolidinyloxy (Acros) (Li et al., 1997). Larvae were dissected, and reactions with proxyl fluorescamine were begun, at 2-h intervals to standardize the reaction time. Following a 2-h reaction on ice in the dark, samples were filtered to HPLC vials, flushed with nitrogen, and $30-\mu \mathrm{l}$ aliquots were injected on a C18 column (4.6 x 250 mm) (Vydak, Hesperia, CA). Injected compounds were eluted isocratically with a 65\% methanol:35\% sodium acetate buffer (50 mM, pH 4) mobile phase at a flow rate of $1 \mathrm{ml} / \mathrm{min}$. Separated compounds were quantified with a fluorescence detector (Shimadzu; $390 \mathrm{~nm}$ excitation, $490 \mathrm{~nm}$ emission) and a Shimadzu CR4A computer (Columbia, MD). The low background levels of hydroxyl radicals in the gut fluids of control insects were subtracted from the hydroxyl radical levels in tannin-feeding larvae, providing a measure of the net production of hydroxyl radicals resulting from tannin oxidation. 
Hydroxyl radical intensity was defined as the Omethyl hydroxylamine peak area/sample mass.

The identity of the O-methyl hydroxylamine reaction product was determined with HPLC by the elution time of a standard, and by determining the mass spectra of reaction products and the standard (Micromass Quatro LC mass-spectrometer, Beverly, MA). An O-methyl hydroxylamine standard was produced in a Fenton reaction mixture containing 1 $\mathrm{mM}$ hydrogen peroxide, $100 \mu \mathrm{M}$ ferric chloride, 1 $\mathrm{mM}$ ascorbate, $100 \mu \mathrm{M}$ ethylenediaminetetracetate (EDTA), and $3 \mathrm{mM}$ proxyl fluorescamine. Fractions containing O-methyl hydroxylamine from Fenton reaction products and $M$. disstria gut fluid were collected for MS by eluting them from the C18 column with a gradient of $80 \%$ double-distilled water containing $0.05 \%$ formate: $20 \%$ acetonitrile to $5 \%$ water: $95 \%$ acetonitrile over a period of $18 \mathrm{~min}$. Collected fractions were infused directly into the MS $(20 \mu \mathrm{l} / \mathrm{min})$, which was operated in the positive ion electrospray mode. The mass fragments produced by both the standard and gut fluid samples (e.g., $m / z$ 437.5) were consistent with $\mathrm{O}$ methyl hydroxylamine as the parent compound.

\section{Protein Carbonyls}

Protein carbonyls were measured in the midgut fluid of M. disstria as a marker of hydroxyl radical damage. Larvae were placed at random in Petri dishes with diet containing $0.5 \%$ ascorbate and 0 or $5 \%(\mathrm{w} / \mathrm{v})$ tannic acid. Midgut contents were extracted in $300 \mu \mathrm{l}$ of $\mathrm{pH} 7.0$ phosphate buffer (50 $\mathrm{mM}$, nitrogen-purged) under a nitrogen atmosphere. Samples ( $\mathrm{n}=9$ control and treatment replicates) were stored at $-80^{\circ} \mathrm{C}$ ( 6 weeks). Protein carbonyls were measured in thawed extracts (kept on ice) after centrifugation $\left(8,000 \mathrm{~g}, 5 \mathrm{~min}, 4^{\circ} \mathrm{C}\right)$, and $200 \mu \mathrm{l}$ of the supernatant solutions were treated with streptomycin sulfate $(22.2 \mu \mathrm{l} ; 10 \% \mathrm{w} /$ $\mathrm{v}$ in $50 \mathrm{mM}$ pH 7.0 HEPES buffer) (Reznick and Packer, 1994; Quinlan and Gutteridge, 2000). After additional centrifugation $\left(8,000 \mathrm{~g}, 5 \mathrm{~min}, 4^{\circ} \mathrm{C}\right)$, proteins remaining in the supernatant solution were precipitated with trichloroacetic acid (100 $\mu \mathrm{l}$, $28 \% \mathrm{w} / \mathrm{v}$ ). Protein pellets were treated with 500 $\mu \mathrm{l}$ of $7 \mathrm{mM}$ 2,4-dinitrophenylhydrazine (DNPH, Acros) in $2 \mathrm{M}$ hydrochloric acid $\left(37^{\circ} \mathrm{C}, 15 \mathrm{~min}\right)$. Treated protein pellets were washed free of unbound DNPH, and solubilized in a guanidine hydrochloride solution (6 M; Acros) as described by Quinlan and Gutteridge (2000). An extinction coefficient of 22,000/M for the DNPH-protein carbonyl adduct at $370 \mathrm{~nm}$ was used to calculate protein carbonyl concentrations (Reznick and Packer, 1994; Quinlan and Gutteridge, 2000). Correction for interfering substances (e.g., tannic acid) at $370 \mathrm{~nm}$ was made by running DNPH-free controls, and subtracting these values from protein carbonyls measurements. Protein concentrations in the sample supernatants were measured with the modified Bradford assay, and quantified with a bovine serum albumin standard curve (Stoscheck, 1990). Protein carbonyl levels were expressed as $\mathrm{nmol}$ protein carbonyl/mg protein.

\section{Iron in Insects and Diets}

Larvae were fed artificial diets containing 0.5\% ascorbate and 0 or $5 \%$ tannic acid during the experimental period. The anterior and posterior midgut contents of $M$. disstria were extracted in 2-ml microcentrifuge tubes containing $1 \mathrm{M}$ hydrochloric acid ( 250 or $300 \mu \mathrm{l}$, made with nitrogen-purged double-distilled water). The contents from two or three insects were pooled per replicate to obtain a fresh weight of at least $50 \mathrm{mg}$. The weights of gut contents were measured to the nearest $0.1 \mathrm{mg}$. Sample collection tubes were kept on ice and flushed with nitrogen at all times. Samples from control $(\mathrm{n}=12)$ and treatment larvae $(\mathrm{n}=12)$ were dissected in alternating order during 1.5- to 2.5-h periods on two successive days. Gut fluid volumes were estimated as $95 \%$ of their fresh weights (Barbehenn et al., 2001). There was a negligible increase in water content $(<1 \%)$ from the anterior to the posterior midgut in both caterpillar species, and no effect of diet treatment on water content in either species (unpublished data). Iron was measured in fresh supernatant solutions with the phenanthroline method, as described below.

Iron concentrations were measured in O. leuco- 
stigma larvae that fed on diets of the same composition as those prepared for M. disstria. Entire midgut contents were pooled from 1-3 larvae to obtain a total fresh weight of at least $50 \mathrm{mg}$ per replicate. Gut contents were extracted in 250 or $300 \mu \mathrm{l}$ of 1 $M$ hydrochloric acid, and iron was measured with the phenanthroline method in fresh supernatant solutions, as described below. The experiment was repeated on a second day.

Iron was measured in the midgut fluids of penultimate- and final-instar $M$. disstria that fed on red oak (Quercus rubra) for a two-day period (beginning the 25th or 26th of June 2002). Twigs containing clusters of five leaves were cut haphazardly with a pole pruner from the sunlit side of trees at the University of Michigan. Leaves were coated with $200 \mu \mathrm{l}$ of $85 \%$ acetone or $85 \%$ acetone containing $50 \mathrm{mg} / \mathrm{ml}$ tannic acid to produce an increase of 5\% dry weight. A micropipet was used to dispense the solvent evenly across each leaf, placing the pipette tip parallel to the leaf surface to avoid scratching the leaf. The percent dry weight of the added tannin was calculated based on the mean fresh weight:dry weight ratio of untreated leaves. Twigs were placed in water in $15-\mathrm{ml}$ centrifuge tubes that were taped inside ventilated plastic shoe boxes. Larvae were assigned at random to each treatment and placed in boxes in an incubator. Freshly-treated leaves from different trees were provided daily. After two days, larvae were dissected, alternating between control $(n=10)$ and treatment $(\mathrm{n}=13)$ replicates. The contents of the entire midgut from between 1-5 larvae were pooled per replicate to obtain sample weights of at least $80 \mathrm{mg}$. Gut fluid volumes were approximated as $90 \%$ of the fresh weight (Barbehenn et al., 2003b). Iron was measured in fresh supernatant samples with the phenanthroline method as described below, with the exception that only total iron was measured by including ascorbate in all samples.

Iron concentrations were measured in the experimental artificial diets containing $0 \%$ or $5 \%$ tannic acid. Samples of each diet $(100 \mathrm{mg} ; \mathrm{n}=10$ / treatment) were homogenized in $500 \mu \mathrm{l}$ of $1 \mathrm{M}$ hydrochloric acid (nitrogen-purged) using a glass hand-held tissue homogenizer. After centrifugation, iron was measured in the supernatant solutions, as described below for gut fluid samples.

To test whether iron was contributed by the tannic acid added to treated food, the total iron content of tannic acid was determined with ion-coupled plasma mass spectrometry (ICP-MS; Finnigan MAT ELEMENT ICP) (Thermo Electron Corp., Schaumberg, IL). Samples ( $5 \mathrm{mg} ; \mathrm{n}=4$ ) were weighed to the nearest $0.1 \mathrm{mg}$ into $200-\mu \mathrm{l}$ microcentrifuge tubes with screw-cap lids. Samples were digested in concentrated nitric acid ( $250 \mu \mathrm{l}$; trace analysis grade) (Fluka, Milwaukee, WI) and hydrogen peroxide $(250 \mu \mathrm{l} ; 30 \% \mathrm{w} / \mathrm{v}$, Sigma) in a boiling water bath $(1 \mathrm{~h})$. Digestates were transferred to $15-\mathrm{ml}$ plugseal cap polypropylene centrifuge tubes (Fisher Scientific, Pittsburgh, PA) and diluted to a total volume of $5.0 \mathrm{ml}$ with double-distilled water. Diluted digestates and blanks were analyzed directly.

\section{Iron Analyses}

The phenanthroline assay measures reduced iron [Fe (II)] (Brumby and Massey, 1967). When used with ascorbate to reduce Fe (III), total iron is measured. The phenanthroline assay was adapted to fit the $200-\mu \mathrm{l}$ wells of a 96 -well micro-titer plate. Fresh sample extracts were centrifuged $(8,000 g ; 4$ min), and supernatant solutions were transferred to new tubes, which were flushed with nitrogen and stored at ambient temperature until analyzed (0.5-2.5 h). Supernatant solutions were treated with $20 \%(\mathrm{w} / \mathrm{v})$ trichloroacetic acid (prepared with nitrogen-purged double-distilled water) at a ratio of 1:3 TCA:sample. After incubation for $10 \mathrm{~min}$ under a nitrogen atmosphere, the samples were centrifuged $(8,000 \mathrm{~g} ; 4 \mathrm{~min})$. To each microplate well was added $72 \mu \mathrm{l}$ of nitrogen-purged doubledistilled water, $32 \mu \mathrm{l}$ of 1,10 -phenanthroline $(0.1 \%$ $\mathrm{w} / \mathrm{v}$ in nitrogen-purged double-distilled water), and $8 \mu \mathrm{l}$ of $120 \mathrm{mM}$ ascorbic acid (for total iron) or 8 $\mu \mathrm{l}$ of $60 \mathrm{mM}$ acetic acid (for reduced iron). Finally, $80 \mu \mathrm{l}$ of sample supernatant solutions and $8 \mu \mathrm{l}$ of saturated ammonium acetate were added to the wells. Microplates were mixed, and sample absorbances (540 nm) were measured with a Biorad Benchmark microplate reader (Hercules, CA). 
Blanks (containing nitrogen-purged double-distilled water instead of the phenanthroline solution) were run for each sample, and the blank absorbance was subtracted from the sample absorbance. Ferrous sulfate standards were serially diluted in 1 $M$ hydrochloric acid (low oxygen). Standard curves for the phenanthroline assay were linear over a range from 0 to $500 \mu \mathrm{M}$ ferrous sulfate. All reagents were prepared fresh daily.

The phenanthroline method was judged to be accurate based upon the following comparisons and tests: (1) Similar concentrations of total iron were measured in midgut fluid samples with the phenanthroline method and ICP-MS (Barbehenn and Martin, 1998). (2) The total iron concentration measured with the phenanthroline assay in Acer saccharum ( $29 \mu \mathrm{g} / \mathrm{g}$ fresh weight) was similar to total iron levels measured previously with this assay in a wide range of plant leaves (Mehrota and Gupta, 1990). (3) Total iron recovered from control and 5\% tannic acid diet extracts spiked with ferrous sulfate averaged $99.7 \%$, suggesting that no substances interfered with the assay once the samples were extracted. (4) Iron (III) (ferric chloride) was not measurable with the phenanthroline assay unless it was treated with ascorbate. The efficiency of reduction of Fe (III) by ascorbate in the assay was $89.7 \%$. In addition, total iron levels in the midgut tissues of $M$. disstria $(127 \pm 8 \mu \mathrm{M}$ for control larvae and $122 \pm 10 \mu \mathrm{M}$ for treatment larvae) were sufficiently small that contamination of midgut fluid along the length of the incision would cause negligible increases in iron concentrations.

\section{Statistical Analysis}

No significant differences were observed between days in repeated experiments, and the data were pooled within treatments for analysis. Mean iron concentrations in individual $M$. disstria larvae were calculated from the anterior and posterior sections for comparison of overall iron concentrations with O. leucostigma. Iron concentrations in the midgut fluids of the two caterpillar species were compared using two-way ANOVA, with species and treatment as fixed effects (SAS, 2000). A repeated measures two-way ANOVA was used to compare iron concentrations between regions of the midgut in M. disstria, with treatment and experiment date as fixed effects, and site as a repeated effect. Tests of normality were made using PROC UNIVARIATE (SAS, 2000). Kruskal-Wallis tests (nonparametric) were used to compare hydroxyl radical intensities, protein carbonyl levels, and the fraction of Fe (II) across species and treatments (Wilkinson, 2000). Pairwise differences between means were examined by differences of least squares means generated by PROC MIXED (SAS, 2000), or by Kruskal-Wallis tests.

\section{RESULTS}

Higher levels of hydroxyl radicals were formed in the midgut fluids of $M$. disstria than in $O$. leucostigma larvae that fed on a diet containing tannic acid (Fig. 1; $P<0.001$ ), supporting the first hypothesis. A small, but significant, increase in hydroxyl radical levels was detected in the posterior midgut of O. leucostigma larvae. Hydroxyl radicals were undetectable in the acidic foregut of $M$. disstria. A marker of the oxidative damage produced by hydroxyl radicals, protein carbonyls, increased $160 \%$ in the midgut fluids of $M$. disstria that fed on a tannin-containing diet (Fig. $2 ; P<0.001$ ).

Contrary to the second hypothesis, the midgut fluids of O. leucostigma and M. disstria contained similar total iron concentrations when feeding on artificial diets (Fig. 3). If the iron in the diet was fully solubilized $(1,000 \mu \mathrm{M})$ but was diluted by the higher water content of the midgut fluid (to $840 \mu \mathrm{M}$ ), then the iron present in the supernatant solutions from midgut fluids represented only a small fraction $(<10 \%)$ of the total iron contained in the ingested diets. This calculation assumes that there was no net absorption of iron from the midgut (Locke and Leung, 1984).

Unexpectedly, when O. leucostigma and $M$. disstria larvae ingested a diet containing tannic acid, iron concentrations increased significantly in their midgut fluids $(P<0.001)$. Iron concentrations also increased $55 \%$ in $M$. disstria that ingested red oak leaves treated with tannic acid, from $44.5 \pm 3.7$ 


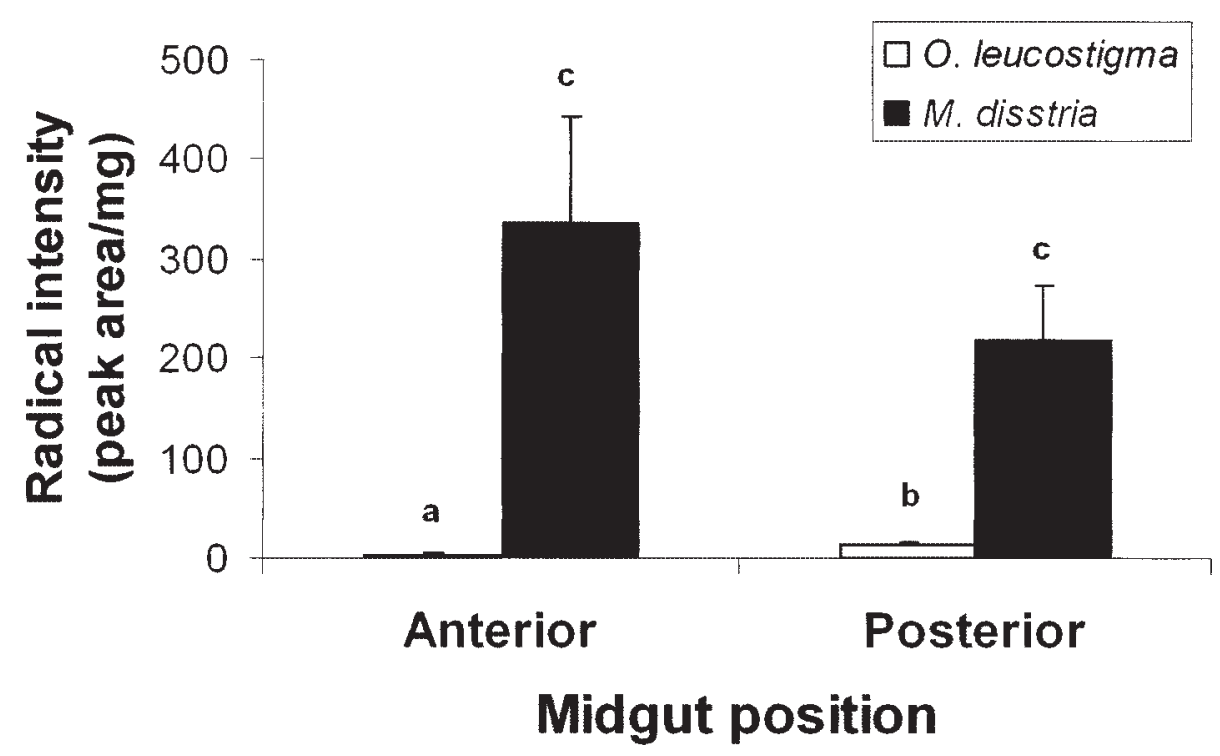

Fig. 1. Hydroxyl radical levels in the midgut fluids of final-instar O. leucostigma and M. disstria larvae. $\mu \mathrm{M}$ on control leaves to $68.9 \pm 6.6 \mu \mathrm{M}$ on tannintreated leaves $(P=0.008)$. O. leucostigma showed a similar trend towards increasing total iron concentrations in larvae on tannin-treated red oak leaves (unpublished data). Based on an estimated total iron concentration of $600 \mu \mathrm{M}$ in red oak leaves (Allen, 1974), the iron remaining in the midgut fluids of $M$. disstria was again on the order of $10 \%$ of that found in the oak leaves. This calculation was based on an estimated dilution factor of $71 \%$ from foliar to gut fluid water content. Iron concentrations did not change significantly along the length of the midgut in M. disstria (Fig. 4).

A surprisingly large fraction of the iron that remained in solution or suspension in the midgut fluid of M. disstria was in the reduced form (Table 1). Similarly, iron in the midgut fluids of $O$. leucostigma was almost completely in the reduced state (98\% in control and tannin-feeding larvae), based on a lack of effect from ascorbate added in the phenanthroline assay. The fraction of iron present as $\mathrm{Fe}$ (II) in $M$. disstria decreased significantly along the length of the midgut $(P<0.05)$. However, the percentage of $\mathrm{Fe}$ (II) did not differ significantly between control and tannin-feeding insects at either position in the midgut.

Iron concentrations measured in tannin-containing diet $(59.9 \pm 4.0 \mu \mathrm{M})$ were not significantly different from those in tannin-free diet $(69.6 \pm 4.3$ $\mu \mathrm{M})(P=0.112)$. Similar results were observed in

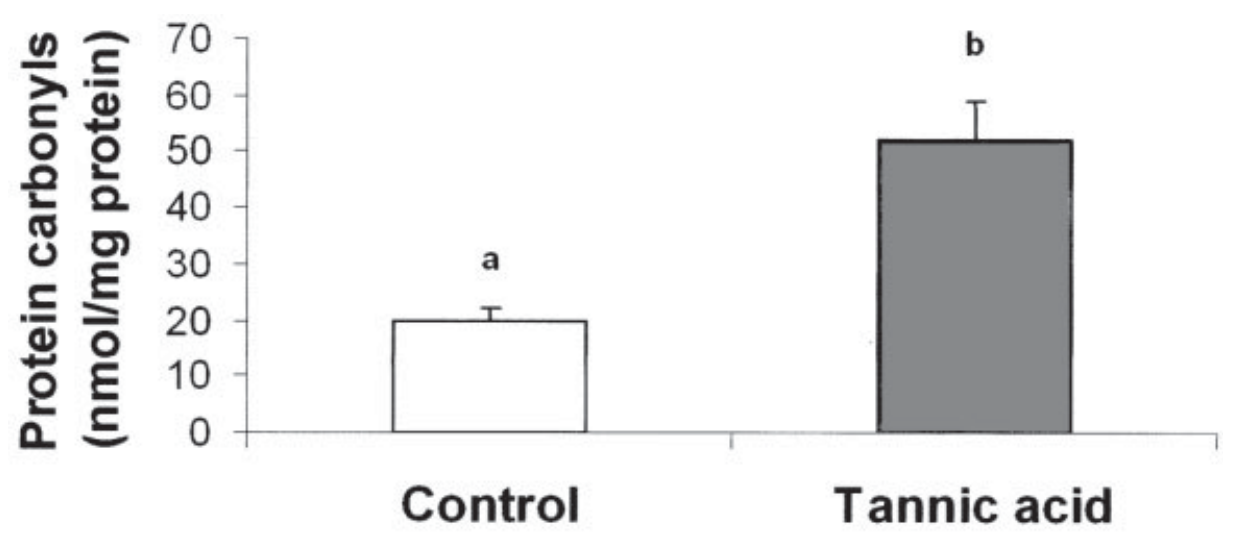

Food type
Fig. 2. Protein carbonyls formed in the midgut fluids of final-instar M. disstria larvae that fed on a tannin-free control diet or a diet containing tannic acid (5\% dry weight). 


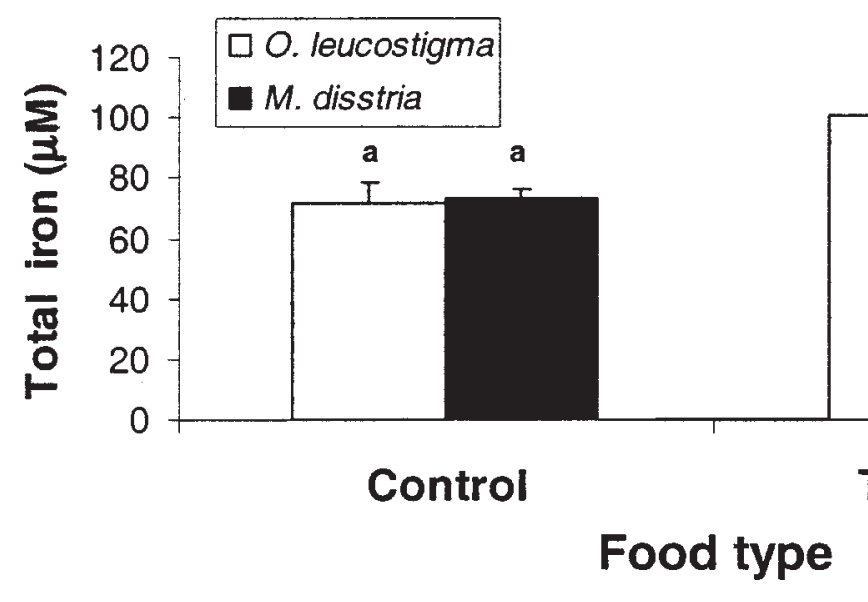

a preliminary assay. It is noteworthy that these results were the opposite of the pattern of iron concentrations in the midgut fluids of larvae that fed on the two artificial diet treatments. A negligible amount of iron was measured in tannic acid with ICP-MS (0.028 $\mu \mathrm{mol}$ iron/g tannic acid).

\section{DISCUSSION}

The results of this study support the hypothesis that higher levels of hydroxyl radicals are formed in the midgut fluids of the phenol-sensitive caterpillar M. disstria than in the phenol-tolerant caterpillar O. leucostigma. However, contrary to the second hypothesis, $M$. disstria and O. leucostigma maintain similar Fe (II) concentrations in solution or colloidal suspension in their midgut fluids. Thus, it can be inferred that higher levels of hydroxyl radicals form in $M$. disstria as a result of higher hydrogen peroxide concentrations in this species (Barbehenn et al., 2001), rather than from higher levels of catalytic metal ions.

As in other biological systems, most of the soluble or colloidal iron in gut fluids would likely be present in complexes, such as with proteins, carbohydrates, phosphate, organic acids, and polar lipids (Halliwell and Gutteridge, 1986). Since over $90 \%$ of the iron ingested by caterpillars is not in

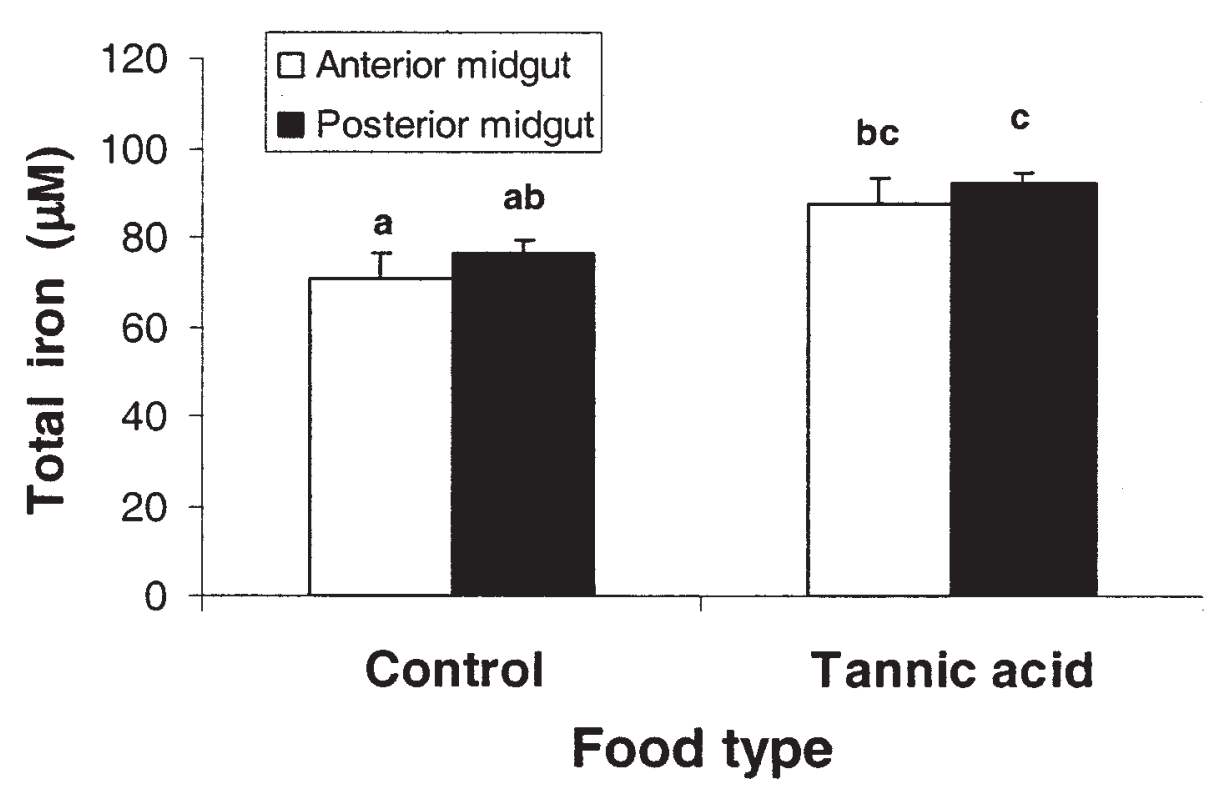

Fig. 4. Total iron [Fe (II) + $\mathrm{Fe}$ (III)] concentrations in the anterior and posterior midgut fluids of final-instar M. disstria larvae that fed on a tanninfree control diet or a diet containing tannic acid (5\% dry weight). 
TABLE 1. The Percentage of Reduced Iron [Fe (II)] in the Midgut Fluids of $M$. disstria Larvae on 0 or $5 \%$ Tannic Acid-Containing Diet*

\begin{tabular}{llll}
\hline Diet & Midgut & & \\
position & Fe (II) (\%) & N \\
\hline Control & Anterior & $97.4 \pm 2.2^{\mathrm{c}}$ & 12 \\
Control & Posterior & $90.9 \pm 2.5^{\text {ab }}$ & 12 \\
Tannic acid & Anterior & $94.2 \pm 3.1^{\mathrm{bc}}$ & 12 \\
Tannic acid & Posterior & $86.8 \pm 2.4^{\mathrm{a}}$ & 12 \\
\hline
\end{tabular}

${ }^{*}$ Data are presented as mean \pm SE. Different superscript letters designate significant differences between the four means $(P<0.05)$.

solution or suspension following centrifugation of the midgut contents, ingested iron is presumed to be associated largely with particulate matter (e.g., cell wall components and the peritrophic envelope) and/or present in insoluble forms (Schneider, 1988). The latter possibility appears to be likely in the case of artificial diets, given the low extractability of iron from artificial diets in this study. Oxidative damage to particulate matter by hydroxyl radicals formed at iron-binding sites in this matter would probably have little effect on insect performance (Pascoa et al., 2002; Barbehenn and Stannard, 2004).

Further work is needed to determine the extent to which oxidative damage to limiting nutrients, such as protein, affects the fitness of caterpillars. Surprisingly, despite the extensive oxidation of tannic acid and the increased oxidation of protein in the midgut lumen of $M$. disstria, no measurable effects on growth and consumption rates or nitrogen digestion efficiencies have been observed (Karowe, 1989; Barbehenn and Martin, 1994). This suggests a potentially important role for post-ingestive compensatory mechanisms in insects in which high levels of oxidation occur, such as the secretion of more proteases (Broadway and Duffey, 1986).

Iron appears to exist primarily in the reduced state in the midgut fluids of $M$. disstria and $O$. leucostigma. This large fraction of Fe (II) could result from a combination of redox cycling by antioxidants, such as ascorbate (Barbehenn et al., 2001), low levels of molecular oxygen (Johnson and Barbehenn, 1999), and/or other factors that contribute to the low redox potential in the midgut fluids of M. disstria and O. leucostigma (Barbe- henn and Martin, 1994). The decrease in the fraction of Fe (II) in the posterior midgut of M. disstria is consistent with the marked drop in ascorbate levels in this region (Barbehenn et al., 2001). While we did not measure the fraction of Fe (II) in the midgut fluids of caterpillars that consumed leaves, previous findings on the redox state of iron in leaf homogenates suggest that Fe (II) also would predominate in foliage-feeding caterpillars (Mehrota and Gupta, 1990).

It is possible that the fraction of reduced iron measured in this study could be overestimated if the chelation of Fe (II) by phenanthroline favors the reduction of Fe (III) (Kakhlon and Cabantchik, 2002). However, it is clear that there is sufficient $\mathrm{Fe}$ (II) in the midgut fluids of $\mathrm{M}$. disstria to promote Fenton-type reactions (Reactions 1 and 2); both hydroxyl radical and protein carbonyl levels are increased in midgut fluids that contain elevated levels of peroxides from tannic acid oxidation.

It is not surprising that Fenton-type reactions would occur in midgut fluids containing iron concentrations of $40-100 \mu \mathrm{M}$ and peroxide concentrations in excess of $500 \mu \mathrm{M}$ (Barbehenn et al., 2001). Such iron and peroxide concentrations are on par with those used in in vitro hydroxyl radical-generating systems, e.g., $100 \mu \mathrm{M}$ iron and 1,000 $\mu \mathrm{M}$ hydrogen peroxide.

The increased levels of iron in tannin-consuming caterpillars could be explained by (1) iron extracted from secreted ferritin (Locke and Leung, 1984; Boyer et al., 1990; Aust, 1995; Becana et al., 1998), (2) iron released from epithelial cells that are sloughed at a higher rate in the presence of tannins (Lotem et al., 1996; Madesh et al., 1999; Hoover et al., 2000), and/or (3) iron chelated and retained in solution or suspension by phenolic compounds (Barbehenn and Martin, 1998, and references therein). The observation that iron concentrations do not increase along the length of the midgut in $M$. disstria suggests that iron is not extracted in significant amounts from ferritin secreted into the posterior midgut (Nichol and Locke, 1989). It is unknown whether iron-binding proteins would be released and extracted from sloughed cells along the length of the midgut. However, 
polyphenolate anions and semiquinone radicals formed in high $\mathrm{pH}$ midgut fluids could act as effective chelators of polyvalent metal cations (Kalyanaraman et al., 1985; McDonald et al., 1996; Hider et al., 2001), and prevent iron from precipitating from solution, as does EDTA. Therefore, work is needed to determine whether elevated iron concentrations result from an increased flux of iron into the midgut lumen or a greater retention of ingested iron in solution and colloidal suspension.

The maintenance of an efficient ascorbate recycling system in the midgut fluids of O. leucostigma is necessary to limit the oxidation of ingested phenolic compounds and the subsequent formation of peroxides (Barbehenn et al., 2001). However, as noted above, ascorbate could also function as a prooxidant by reducing Fe (III) to Fe (II), potentially increasing the rates of Fenton-type reactions. Based on this study, we suggest that ascorbate in midgut fluids provides a net antioxidant effect by limiting the formation of the peroxides that are necessary for Fenton-type reactions.

The results of this study strongly suggest that the soluble and colloidal iron in the midgut fluids of tree-feeding caterpillars is not efficiently sequestered in a redox-inactive form. This conclusion is inferred from two main findings: (1) The concentration of iron measured with ICP-MS in midgut fluids, which would include any sequestered forms of iron, is similar to that measured with the phenanthroline assay (Barbehenn and Martin, 1998). (2) Most of the iron measured in midgut fluids appears to be reduced, and some fraction of this iron participates in Fenton-type reactions. The apparent lack of careful sequestration of iron in the midgut distinguishes the antioxidant defenses of midgut fluids from those of many other extracellular fluids, as well as animal and plant tissues in general (Halliwell and Gutteridge, 1986, 1999). Instead, our results point to the importance of maintaining low levels of peroxides as an antioxidant defense of the midgut lumen. Thus, the ability to control the oxidation of ingested phenols in the gut lumen is a key step that would limit Fenton-type reactions in phenol-tolerant caterpillar species.

\section{ACKNOWLEDGMENTS}

We thank Professor Michael M. Martin for suggesting revisions to the manuscript, Dr. Ted Huston for making ICP-MS measurements, and Bob McCron for generously providing the insect eggs. This work was supported by NSF grant IBN9974583 to R.V.B.

\section{LITERATURE CITED}

Allen SE. 1974. Chemical composition of soils and plant materials. In: Allen SE, editor. Analysis of ecological materials. Oxford: Blackwell. p. 508-509.

Aust SD. 1995. Ferritin as a source of iron and protection from iron-induced toxicities. Toxicol Lett 82/83: 941-944.

Babbs CF, Steiner MG. 1990. Detection and quantification of hydroxyl radical using dimethyl sulfoxide as molecular probe. Methods Enzymol 186: 137-147.

Barbehenn RV, Martin MM. 1992. The protective role of the peritrophic membrane in the tannin-tolerant larvae of Orgyia leucostigma (Lepidoptera). J Insect Physiol 38:973980 .

Barbehenn RV, Martin MM. 1994. Tannin sensitivity in Malacosoma disstria: roles of the peritrophic envelope and midgut oxidation. J Chem Ecol 20:1985-2001.

Barbehenn RV, Martin MM. 1998. Formation of insoluble and colloidally dispersed tannic acid complexes in the midgut fluids of Manduca sexta (Lepidoptera: Sphingidae): an explanation for the failure of tannic acid to cross the peritrophic envelopes of lepidopteran larvae. Arch Insect Biochem Physiol 39:109-117.

Barbehenn RV, Stannard J. 2004. Antioxidant defense of the midgut epithelium by the peritrophic envelope in caterpillars. J Insect Physiol 50:783-790.

Barbehenn RV, Martin MM, Hagerman AE. 1996. Reassessment of the roles of the peritrophic envelope and hydrolysis in protecting polyphagous grasshoppers from ingested hydrolyzable tannins. J Chem Ecol 22:1911-1929.

Barbehenn RV, Bumgarner SL, Roosen EF, Martin MM. 2001. Antioxidant defenses in caterpillars: role of the ascorbaterecycling system in the midgut lumen. J Insect Physiol 47:349-357. 
Barbehenn RV, Poopat U, Spencer B. 2003a. Semiquinone and ascorbyl radicals in the gut fluids of caterpillars measured with EPR spectrometry. Insect Biochem Mol Biol 33:125-130.

Barbehenn RV, Walker AC, Uddin F. 2003b. Antioxidants in the midgut fluids of a tannin-tolerant and a tannin-sensitive caterpillar: effects of seasonal changes in tree leaves. J Chem Ecol 29:1099-1116.

Becana M, Moran JF, Iturbe-Ormaetxe I. 1998. Iron-dependent oxygen free radical generation in plants subjected to environmental stress: toxicity and antioxidant protection. Plant Soil 201:137-147.

Boyer RF, McArthur JS, Cary TM. 1990. Plant phenolics as reductants for ferritin iron release. Phytochemistry 29: 3717-3719.

Bravo L. 1998. Polyphenols: chemistry, dietary sources, metabolism, and nutritional significance. Nutr Rev 56:317-333.

Broadway RM, Duffey SS. 1986. Plant protease inhibitors: mechanism of action and effect on the growth and digestive physiology of larval Heliothis zea and Spodoptera exigua. J Insect Physiol 32:827-833.

Brumby PE, Massey V. 1967. Determination of nonheme iron, total iron, and copper. Methods Enzymol 10:463-474.

Buettner G. 1993. The pecking order of free radicals and antioxidants: lipid peroxidation, $\alpha$-tocopherol, and ascorbate. Arch Biochem Biophys 300:535-543.

Davies MJ, Fu S, Wang H, Dean RT. 1999. Stable markers of oxidant damage to proteins and their application in the study of human disease. Free Rad Biol Med 27:1151-1163.

Felton GW. 1996. Nutritive quality of plant protein: sources of variation and insect herbivore responses. Arch Insect Biochem Physiol 32:107-130.

Felton GW, Summers CB. 1995. Antioxidant systems in insects. Arch Insect Biochem Physiol 29:187-197.

Guha MM, Mitchell RL. 1966. The trace and major element composition of the leaves of some deciduous trees. Plant Soil 24:90-112.

Hagerman AE, Butler LG. 1991. Tannins and lignins. In: Rosenthal GA, Berenbaum MR editors. Herbivores: their interactions with secondary plant metabolites. San Diego: Academic Press. p 355-388.
Halliwell B, Gutteridge JMC. 1986. Oxygen free radicals and iron in relation to biology and medicine: some problems and concepts. Arch Biochem Biophys 246:501-514.

Halliwell B, Gutteridge JMC. 1999. Free radicals in biology and medicine. Oxford: Oxford University Press, 936 p.

Hider RC, Liu ZD, Khodr HH. 2001. Metal chelation of polyphenols. Methods Enzymol 335:190-203.

Hoover K, Washburn JO, Volkman LE. 2000. Midgut-based resistance of Heliothis virescens to baculovirus infection mediated by phytochemicals in cotton. J Insect Physiol 46:999-1007.

Johnson KS, Barbehenn RV. 1999. Oxygen levels in the gut lumens of herbivorous insects. J Insect Physiol 46:897903.

Kakhlon O, Cabantchik ZI. 2002. The labile iron pool: characterization, measurement, and participation in cellular processes. Free Rad Biol Med 33:1037-1046.

Kalyanaraman B, Felix CC, Sealy RC. 1985. Semiquinone anion radicals of catechol(amine)s, catechol estrogens, and their metal ion complexes. Environ Health Perspect 64:185-198.

Karowe DN. 1989. Differential effect of tannic acid on two tree-feeding Lepidoptera: implications for theories of plant-herbivore chemistry. Oecologia 80:507-512.

Levine RL, Garland D, Oliver CN, Amici A, Climent I, Lenz A-G, Ahn B-W, Shaltiel S, Stadtman ER. 1990. Determination of carbonyl content in oxidatively modified proteins. Methods Enzymol 186:464-478.

Li B, Gutierrez PL, Blough NV. 1997. Trace determination of hydroxyl radical in biological systems. Anal Chem 69:42954302.

Li B, Gutierrez PL, Blough NV. 1999. Trace determination of hydroxyl radical using fluorescence detection. Methods Enzymol 300:202-216.

Locke M, Leung H. 1984. The induction and distribution of an insect ferritin: a new function for the endoplasmic reticulum. Tissue Cell 16:739-766.

Locke M, Nichol H. 1992. Iron economy in insects:transport, metabolism, and storage. Annu Rev Entomol 37:195-215.

Lotem J, Peled-Kamar M, Groner Y, Sachs L. 1996. Cellular Archives of Insect Biochemistry and Physiology 
oxidative stress and the control of apoptosis by wild-type p53, cytotoxic compounds, and cytokines. Proc Natl Acad Sci USA 93:9166-9171.

Madesh M, Benard O, Balasubramanian KA. 1999. Apoptotic processes in the monkey small intestinal epithelium: 2. Possible role of oxidative stress. Free Rad Biol Med 26:431438.

McDonald M, Mila I, Scalbert A. 1996. Precipitation of metal ions by plant polyphenols: optimal conditions and origin of precipitation. J Agr Food Chem 44:599-606.

Mehrota SC, Gupta P. 1990. Reduction of iron by leaf extracts and its significance for the assay of Fe (II) in plants. Plant Physiol 93:1017-1020.

Nichol H, Locke M. 1989. The characterization of ferritin in an insect. Insect Biochem 19:587-602.

Okuda T, Yoshida T, Hatano T. 1993. Classification of oligomeric hydrolyzable tannins and specificity of their occurrence in plants. Phytochemistry 32:507-521.

Pascoa V, Oliveira PL, Dansa-Petretski M, Silva JR, Alvarenga PH, Jacobs-Lorena M, Lemos FJA. 2002. Aedes aegypti peritrophic matrix and its interaction with heme during blood digestion. Insect Biochem Mol Biol 32:517-523.

Quinlan GJ, Gutteridge JMC. 2000. Carbonyl assay for oxidative damage to proteins. In: Taniguchi N, Gutteridge JMC, editors. Experimental protocols for reactive oxygen and nitrogen species. New York: Oxford University Press. p 257-258.
Reznick AZ, Packer L. 1994. Oxidative damage to proteins: spectrophotometric method for carbonyl assay. Methods Enzymol 233: 357-371.

SAS Institute. 2000. The SAS system for Windows. Version 8e. Cary, NC: SAS Institute.

Schneider W. 1988. Iron hydrolysis and the biochemistry of iron - the interplay of hydroxide and biogenic ligands. Chimia 42:9-20.

Sohal RS, Allen RG, Farmer KJ, Newton RK. 1985. Iron induces oxidative stress and may alter the rate of aging in the housefly, Musca domestica. Mech Age Dev 32:33-38.

Stadtman ER. 1990. Metal ion-catalyzed oxidation of proteins: biochemical mechanism and biological consequences. Free Rad Biol Med 9:315-325.

Stoscheck CM. 1990. Increased uniformity in the response of the Coomassie blue $\mathrm{G}$ protein assay to different proteins. Anal Biochem 184:111-116.

Summers CB, Felton GW. 1994. Prooxidant effects of phenolic acids on the generalist herbivore Helicoverpa zea (Lepidoptera: Noctuiidae): potential mode of action for phenolic compounds in plant anti-herbivore chemistry. Insect Biochem Mol Biol 24:943-953.

Welch KD, Davis TZ, Van Eden ME, Aust SD. 2002. Deleterious iron-mediated oxidation of biomolecules. Free Rad Biol Med 32:577-583.

Wilkinson L. 2000. SYSTAT: The system for statistics. Evanston, IL: SYSTAT, Inc. 